OPEN ACCESS

Edited by:

Maw Pin Tan,

University of Malaya, Malaysia

Reviewed by:

Annalisa Setti,

University College Cork, Ireland

Kathy E. Sykes,

United States Environmental

Protection Agency (US EPA),

United States

*Correspondence:

Constance Wang

wangconstance@gmail.com

Specialty section:

This article was submitted to Public Health Education and Promotion,

a section of the journal

Frontiers in Public Health

Received: 28 September 2016

Accepted: 06 June 2017

Published: 02 August 2017

Citation:

Satariano WA, Wang C, Kealey ME, Kurtovich E and Phelan EA (2017) Risk Profiles for Falls among Older Adults: New Directions for Prevention.

Front. Public Health 5:142. doi: 10.3389/fpubh.2017.00142

\section{Risk Profiles for Falls among Older Adults: New Directions for Prevention}

\author{
William A. Satariano ${ }^{1}$, Constance Wang ${ }^{1 *}$, Melissa E. Kealey ${ }^{1}$, Elaine Kurtovich ${ }^{1}$ and \\ Elizabeth A. Phelan ${ }^{2,3}$
}

\begin{abstract}
'School of Public Health, University of California Berkeley, Berkeley, CA, United States, ${ }^{2}$ Department of Medicine, Division of Gerontology and Geriatric Medicine, School of Public Health, University of Washington, Seattle, WA, United States,

${ }^{3}$ Department of Health Services, School of Public Health, University of Washington, Seattle, WA, United States
\end{abstract}

Objective: To address whether neighborhood factors, together with older adults' levels of health and functioning, suggest new combinations of risk factors for falls and new directions for prevention. To explore the utility of Grade-of-Membership (GoM) analysis to conduct this descriptive analysis.

Method: This is a cross-sectional, descriptive study of 884 people aged $\geq 65$ years from Alameda County, CA, Cook County, IL, Allegheny County, PA, and Wake and Durham counties, NC. Interviews focused on neighborhood characteristics, physical and cognitive function, walking, and falls and injuries. Four risk profiles (higher order interactions of individual and neighborhood factors) were derived from GoM analysis.

Results: Profiles 1 and 2 reflect previous results showing that frail older adults are likely to fall indoors (Profile 1); healthy older adults are likely to fall outdoors (Profile 2). Profile 3 identifies the falls risk for older with mild cognitive impairment living in moderately walkable neighborhoods. Profile 4 identifies the risk found for healthy older adults living in neighborhoods with low walkability.

Discussion: Neighborhood walkability, in combination with levels of health and functioning, is associated with both indoor and outdoor falls. Descriptive results suggest possible research hypotheses and new directions for prevention, based on individual and neighborhood factors.

Keywords: aged, falls, neighborhood, walking, community, prevention, descriptive analysis

\section{INTRODUCTION}

Falls are the leading cause of fatal and non-fatal injuries among adults aged 65 years and older (older adults). Every year, approximately $30 \%$ of U.S. adults aged 65 years and older fall (1). Ten percent of those falls result in hospitalization or death. During 2014, approximately 27,000 older adults died because of fall; 2.8 million were treated in emergency departments for fall-related injuries, and approximately 800,000 of these patents were subsequently hospitalized. Direct medical costs related to falls in the U.S. were approximately $\$ 30$ billion in 2010 , and these costs are expected to increase to as much as $\$ 54.9$ billion by 2020 , according to data from the Centers for Disease Control and Prevention [https://www.cdc.gov/HomeandRecreationalSafety/Falls/fallcost.html; Bergen et al. (2)].

Given its clinical and public health significance, there is a need to understand the full scope or "heterogeneity" of falls, i.e., variation in the characteristics of those who fall as well as the location 
and circumstances of the fall itself $(3,4)$. Most research to date has focused on indoor falls (4-6). Less attention has been given to falls that occur outdoors, which represent $40-60 \%$ of all falls by some accounts $(3,4)$. Given that those who fall outdoors tend to be healthier and more fit than those who fall indoors, outdoor environmental hazards are thought to be implicated, with sidewalks and parking garages being identified as common sites of outdoor falls $(3,4,7)$.

While this research, especially the introduction of new neighborhood variables, should expand our understanding of the heterogeneity of falls, it will be challenging. The current approach is to look for risk factors one at a time in saturated regression models adjusted for confounders and other relevant covariates. This approach, while useful for isolating the effect of known factors, does not provide much information on factors not previously examined nor does it provide a straightforward way to look for joint effects of variables across disparate domains. It may be useful, therefore, to look at the effects of individual and environmental factors that tend to occur together in profiles (e.g., routine exercise, history of depression, and residence in a walkable neighborhood) in relation to the occurrence of indoor and outdoor falls.

This exploratory descriptive analysis, then, is designed to determine whether an expanded set of neighborhood variables, together with standard measures of health and functioning, and an innovative analytic strategy, show promise for more detailed study of the heterogeneity of falls $(5,6)$. This, in turn, may suggest new combination of variables to be tested (i.e., hypothesis testing), which is beyond the scope of the current paper.

\section{MATERIALS AND METHODS}

\section{Sample}

This report is based on the Healthy Aging Research Network Walking Study, a cross-sectional study of the association between functional capacity, the neighborhood environment, and walking of older adults living in four regions across the United States (8). The sample consists of 884 people aged $\geq 65$ years identified through senior organizations in Alameda County, CA, Cook County, IL, Allegheny County, PA, and Wake and Durham counties, NC. See the study by Satariano et al. (8) for a detailed description of the sampling design.

The study protocol was approved by the Institutional Review Board at each of the participating universities: the University of California, Berkeley; the University of Illinois, Chicago; the University of Pittsburgh; and the University of North Carolina, Chapel Hill. The interviews were conducted between September 2005 and November 2007. Each respondent provided written, informed consent prior to completing the interview. See Table 1 for a description of the sample characteristics.

\section{Baseline Interview}

The interview included both a questionnaire and direct assessments of physical performance. The questionnaire included demographic and socioeconomic factors; history of falls and injuries; physical function and activities of everyday life (9-11); cognitive function (12-15); depression (16); symptoms associated with walking difficulties; self-reported assessments of neighborhood characteristics (17); and levels of walking and other forms of physical activity. Direct measures of performance were also included, based on measures of walking speed, balance, and lower body strength $(8,18-20)$, and summarized as a modified version of the Short Physical Performance Battery (SPPB) to assess lower body function. The measure of $400 \mathrm{~m}$ walk was chosen as it represents a typical walking distance covered by an older person (21). See the study by Satariano et al. (8) for a more complete description of the modified SPPB.

\section{Measures}

The purpose of the study is to ultimately understand where falls occur as well as the personal and neighborhood attributes of the person falling. Respondents were asked whether they had fallen in the previous 6 months, and whether the most recent fall occurred outdoors or indoors. This report reflects the location of the respondent's most recent fall within the past 6 months. If the respondent fell more than once in the previous 6 months and the location of the most recent fall was different from the location of the previous fall, only information about the most recent fall would be recorded.

\section{Neighborhood Environment: Self-report}

Measurement of the neighborhood environment was based in part on questions from an abbreviated version of the Neighborhood Environment Walkability Scale (NEWS) (17, 22). Fourteen variables were created from the NEWS questions examining primary type of buildings, primary type of housing, walking time to destinations, land-use mix/access to services, street connectivity, walking/cycling facilities, esthetics, pedestrian traffic safety, crime and safety, neighborhood satisfaction/social capital, parking, cul-de-sacs, hilliness, and barriers to walking (e.g., freeways, railway lines, and rivers).

\section{Neighborhood Environment: Geographic Information Systems}

Three geographic information system (GIS) variables were included in the analysis (number of selected types of businesses within a radial distance of each participant's residence, median block length for census tract of residence, and housing density for census tract of residence).

The GIS-derived neighborhood business density variable was based on geocoded environmental data within a 400-m buffer (radial distance) of each participant's residential address (23). ESRI Business Analyst was used, which contains data from InfoUSA for businesses listed on January 1, 2006. Businesses that were possible walking destinations were categorized according to North American Industry Classification System codes and summed to create a count of the number of retail businesses within the $400 \mathrm{~m}$ buffer.

Street connectivity (e.g., median block length) and housing unit density were determined by the census tract of each participant's residence. The U.S. Census 2000 data from the SF3 files was used to measure housing unit density. Median block 
TABLE 1 | Demographics and falls by site compared to county census data.

\begin{tabular}{|c|c|c|c|c|c|c|c|c|c|c|}
\hline & \multicolumn{2}{|c|}{ Alameda County, CA } & \multicolumn{2}{|c|}{ Allegheny County, PA } & \multicolumn{2}{|c|}{ Cook County, IL } & \multicolumn{2}{|c|}{$\begin{array}{l}\text { Wake and Durham } \\
\text { Counties, NC }\end{array}$} & \multicolumn{2}{|c|}{ Total } \\
\hline & Study (\%) & County ${ }^{a}(\%)$ & Study (\%) & County (\%) & Study (\%) & County (\%) & Study (\%) & County (\%) & Study (\%) & $p$ Value $^{\mathrm{b}}$ \\
\hline \multicolumn{11}{|c|}{ Demographic variables } \\
\hline \multicolumn{11}{|l|}{ Age $(n=884)$} \\
\hline $65-74$ & 49.2 & 51.6 & 46.3 & 49.3 & 52.2 & 52.4 & 56.0 & 55.0 & 51.0 & 0.92 \\
\hline $75+$ & 50.8 & 48.4 & 53.7 & 50.7 & 47.8 & 47.6 & 44.0 & 45.0 & 49.0 & \\
\hline \multicolumn{11}{|l|}{$\operatorname{Sex}(n=884)$} \\
\hline Female & 77.4 & 59.3 & 78.6 & 61.0 & 71.4 & 60.5 & 78.4 & 60.7 & 76.6 & $<0.0001$ \\
\hline Male & 22.6 & 40.7 & 21.4 & 39.0 & 28.6 & 39.5 & 21.6 & 39.3 & 23.4 & \\
\hline \multicolumn{11}{|l|}{ Race (n = 866) } \\
\hline Other race & 5.0 & 3.2 & 0.0 & 0.2 & 1.0 & 2.3 & 0.0 & 0.4 & 1.6 & $<0.0001$ \\
\hline Two or more races & 4.2 & 2.5 & 0.0 & 0.4 & 2.5 & 1.3 & 0.4 & 0.6 & 1.8 & \\
\hline African-American & 15.8 & 14.2 & 22.5 & 7.8 & 21.0 & 20.3 & 35.7 & 20.5 & 23.8 & \\
\hline Asian & 13.8 & 17.7 & 1.5 & 0.3 & 0.5 & 3.0 & 7.5 & 1.3 & 6.2 & \\
\hline White & 61.3 & 62.4 & 76.0 & 91.3 & 75.0 & 73.2 & 56.4 & 77.2 & 66.6 & \\
\hline \multicolumn{11}{|c|}{ Latino or Hispanic $(n=871)$} \\
\hline Yes & 5.8 & 8.6 & 0.5 & 0.4 & 3.0 & 5.8 & 1.7 & 0.8 & 2.9 & 0.10 \\
\hline No & 94.2 & 91.4 & 99.5 & 99.6 & 97.0 & 94.2 & 98.3 & 99.2 & 97.1 & \\
\hline \multicolumn{11}{|c|}{ Years of schooling $(n=872)$} \\
\hline $0-11$ years & 7.9 & $N A^{c}$ & 18.9 & NA & 5.5 & NA & 15.7 & NA & 11.9 & \\
\hline 12 years & 19.2 & NA & 51.2 & NA & 32.8 & NA & 30.0 & NA & 32.6 & \\
\hline Over 12 years & 72.9 & NA & 29.9 & NA & 61.7 & NA & 54.3 & NA & 55.5 & \\
\hline \multicolumn{11}{|l|}{ Income $(n=680)$} \\
\hline Less than $\$ 15,000$ & 20.9 & 23.0 & 36.1 & 28.1 & 15.1 & 25.3 & 30.8 & 22.8 & 26.0 & $<0.0001$ \\
\hline$\$ 15,000-\$ 24,999$ & 19.4 & 16.4 & 33.5 & 23.3 & 23.8 & 18.6 & 21.1 & 15.9 & 24.0 & \\
\hline$\$ 25,000-\$ 49,999$ & 32.7 & 27.3 & 23.4 & 28.9 & 38.9 & 28.5 & 25.9 & 28.9 & 29.9 & \\
\hline$\$ 50,000$ or more & 27.0 & 33.3 & 7.0 & 19.7 & 22.2 & 27.6 & 22.2 & 32.4 & 20.1 & \\
\hline \multicolumn{11}{|c|}{ Fallen in the past 6 months $(n=878)$} \\
\hline No & 75.8 & $N A^{c}$ & 87.1 & NA & 74.7 & NA & 87.4 & NA & 81.2 & \\
\hline Yes & 24.2 & NA & 12.9 & NA & 25.3 & NA & 12.6 & NA & 18.8 & \\
\hline \multicolumn{11}{|c|}{ Location of most recent fall, if any $(n=164)$} \\
\hline Indoors & 36.7 & $N A^{c}$ & 57.7 & NA & 53.1 & NA & 58.6 & NA & 48.8 & \\
\hline Outdoors & 63.3 & NA & 42.3 & NA & 44.9 & NA & 41.4 & NA & 50.6 & \\
\hline Do not know & 0 & NA & 0 & NA & 2.0 & NA & 0 & NA & 0.6 & \\
\hline
\end{tabular}

aUS Census 2000 data for adults $65+$.

${ }^{b}$ Overall $p$-value for the chi-square statistic comparing study populations to county populations as measured by the 2000 Census across the four geographic sites.

'NA, Census data categorized in the same way restricted to adults aged 65+ not available.

length data from 2000 from the RAND Center for Population Health and Health Disparities was used to measure street connectivity.

\section{Other Study Variables}

In addition to the full set of demographic, socioeconomic, health, and functional data noted previously, the analysis included study site, access to an automobile, and the number of years at the current residence. See Appendix A in Supplementary Material for a complete list of variables included in the analysis.

\section{Analytic Strategy}

Grade-of-Membership (GoM) analysis was used to identify risk profiles (24-27). GoM is a special case of latent class/latent trajectories models, which uses an algorithmic approach to analyze complex data $(28,29)$. Sets of higher order interactions of independent variables that occur together are identified and are referred to here as "profiles."

Grade-of-Membership analysis is a descriptive approach. GoM is a class of latent structure models. Whereas latent class analysis, another common latent structure model, is used for discrete mixtures, GoM is developed for continuous mixtures.

Grade-of-Membership is designed to identify higher-order interactions (Profiles 1, 2, 3, and 4) associated with outdoor and indoor falls. The profiles suggest hypotheses, which would be test separately, e.g., the independent effect of cognitive function through conditional regression analysis. Testing specific hypotheses, suggested by GoM, is extremely important, but beyond the scope of this introductory, descriptive paper.

Grade-of-Membership analysis was conducted with GoM3 software package following a standardized procedure (30). For this exploratory study, we chose to fit four profiles, rather than to screen and search for the optimal number of profiles that fit the data. Each individual has a matrix of four scores that sum to 1.0; each score reflects the extent to which the individual fits with each of the four identified profiles. Each individual is assigned to only one profile as the best fit for his or her combination of responses across the full range of individual and environmental variables. We used the cut point of GoM score $>0.5$ for a given profile to classify each individual into only one profile. Those 
with a score less than or equal to 0.5 were included in the mixed profile. Analyses were conducted between March and May 2015.

\section{RESULTS}

\section{Sample}

Table 1 compares the distribution of key sociodemographic variables by study site between participants and the general population of residents aged $\geq 65$ years in the corresponding county. These results are generally consistent with a 1984 national survey of senior center users. Overall, $18.8 \%(165 / 878)$ of the participants reported a fall in the previous 6 months (Table 1). Of the 163 who reported the general location of their most recent fall (two of the 165 respondents did not do so), 49.1\% (80/163) indicated that the fall occurred indoors and $50.9 \%$ occurred outdoors (83/163). As noted previously, the percentage difference in the prevalence of indoor and outdoor falls is generally consistent with what is reported in the literature $(4,6,31)$.

\section{Profiles}

Four distinct profiles were identified, based on the data from the full sample of 878 respondents (Appendix A in Supplementary Material; Table 2). For ease of presentation, Appendix A in Supplementary Material reports the distribution of each of 62 variables (rows) by each of the four profiles (columns). From left to right, the columns report the variable name, response categories, and frequency distribution. Following convention, if the frequency for a variable category is 1.8 times its probability for being in the profile, then the variable category is considered to be a "distinguishing" feature of that profile. Each of the distinguishing variable categories is bolded for each of the four profiles (columns 5-8). Table 2 highlights the main points from Appendix A in Supplementary Material by listing the distinguishing variable categories for each profile.

As noted previously, this is an exploratory analysis. The four profiles were employed as a "proof of concept," an exploratory analysis to look at the usefulness of this type of model/results for hypothesis generation. It is not intended to a comprehensive identification of all possible profiles. We did not optimize the modeling or look at overall fit. We chose a 4-profile solution a priori based on prior experience with GoM analysis to see what results it would offer.

Again, this analysis is not designed to assess the independent effects of specific variables. Instead, we were interested in a descriptive analysis to assess the potential utility of identifying higher order interactions, which, in turn, suggest hypotheses for subsequent analyses.

Each of the four profiles is described below. A name was assigned to each profile based on its distinguishing individual and neighborhood features. The four profiles accounted for $75.4 \%$ $(669 / 878)$ of the respondents. In contrast, 209 or $23.8 \%$ could not be so classified and were included in the mixed group.

\section{Profile 1: Frail Older Adults/Poor Neighborhood Walkability}

Of the 878 respondents, $13.3 \%(117 / 878)$ are best classified in Profile 1 . Those in this profile are characterized by poor selfreported health; a variety of limiting symptoms; poor vision; depressive symptoms; poor self-reported cognitive function; and reduced cognitive performance, as measured by the Modified Mini-Mental State Exam. In addition to poor health and functioning, this profile is characterized by participants' reports of the neighborhood being unsafe, with relatively long distances to important destinations, and unattractive surroundings. Finally, those in this profile are likely to be African-American with less than a high school education and an annual income of less than $\$ 15,000$.

\section{Profile 2: Healthy Older Adults/Good Neighborhood Walkability}

Profile 2 includes $18.9 \%$ (166/878) of the participants. In contrast to Profile 1 , the people in this profile are likely to both report and display very good health and functioning. In addition to excellent overall health, there are no reports of limitations associated with specific symptoms, such as leg weakness and shortness of breath. There are no reports of difficulties with ADLs, generic functional tasks, or cognitive function. Indeed, Profile 2 is associated with relatively high scores for both the objective cognitive texts as well as direct measures of physical performance in the highest quartiles. In addition to positive health and functioning, there are reports that are consistent with a very walkable neighborhood, including relatively short walking distance to important destinations. In addition to walkability, this profile is also characterized by access to other forms of mobility, such as driving. With regard to social factors, this profile is characterized by long-term residence of 50-60 years, living with a spouse, providing care to someone outside the home, a relatively large friendship network, being currently employed, with an annual income of $\$ 25,000-\$ 48,999$, and reports that their financial resources are adequate to meet daily needs.

\section{Profile 3: Cognitively Impaired Older Adults/ Moderate Neighborhood Walkability}

Of the 878 respondents, $19.2 \%$ of them are best classified in Profile 3. In general, Profile 3 is characterized by respondents in reasonably good physical health and functional status. Although people in Profile 3 do not tend to report difficulties with cognitive function, they are likely to score in the lowest quartile of the objective cognitive measures. There are also mixed results for neighborhood walkability. While people in Profile 3 are likely to live in areas of high walkability, based on GIS data, they are likely to report general impediments to walking in their neighborhoods, including somewhat low confidence in being able to walk 10 blocks in their neighborhoods. It is also reported that driving and parking a car is difficult in their neighborhood. In terms of socioeconomic status, Profile 3 is characterized by participants with an annual income of less than $\$ 15,000$, an education of less than 12 years, and being unemployed. Like Profile 1, AfricanAmerican or being of mixed racial heritage is a distinguishing feature of Profile 3.

\section{Profile 4: Healthy Older Adults/Poor Neighborhood Walkability}

Nearly a quarter of the 878 respondents (217 or $24.7 \%$ ) are best characterized by Profile 4. Participants in this profile are likely to describe themselves as being in good health and functioning. They are likely not to be concerned about falls, and they have 
TABLE 2 | A summary of the distinguishing categories for the individual and environmental variables by profile.

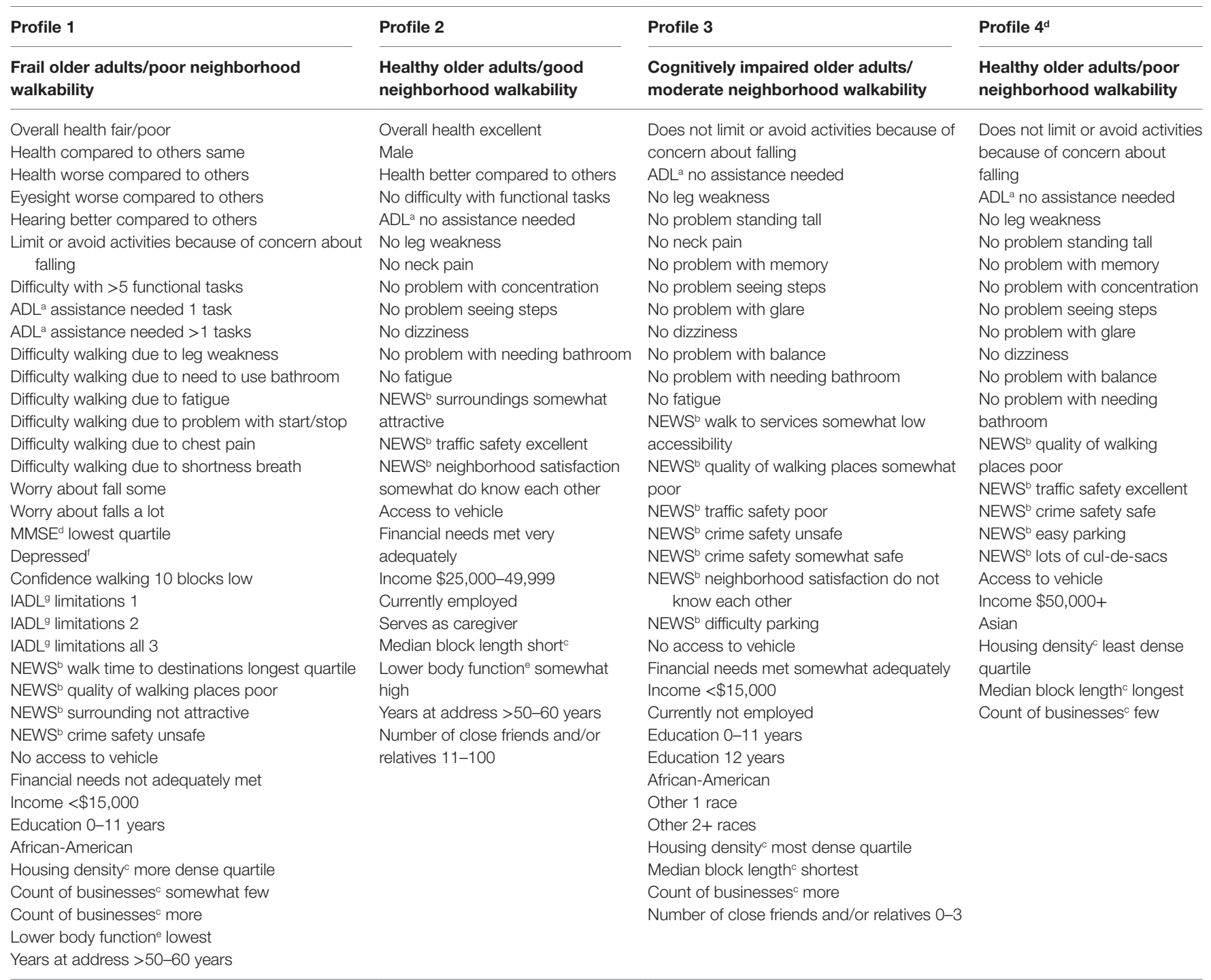

${ }^{a}$ Activities of Daily Living.

${ }^{b}$ Neighborhood Environment Walkability Scale.

${ }^{\circ}$ Geographic Information System variable.

¿Modified Mini-Mental State Exam.

eSummary of direct measures of balance, walking speed, and lower body strength.

${ }^{f}$ Per Center for Epidemiologic Studies Depression Scale.

IInstrumental Activities of Daily Living.

no problems with leading symptoms. They are also not likely to report difficulties associated with cognition, such as poor memory or concentration. Their reports are consistent with high objective assessments of cognition. Finally, they do not report problems with ADL or IADL tasks. However, Profile 4 neighborhoods, as measured by both self-report and objective indicators, are characterized as having low walkability, unlike those of their healthy peers in Profile 2.

\section{Risk of Indoor and Outdoor Falls}

There are a total of 165 falls reported by 878 respondents (18.8\%).

Table 3 reports a statistically significant difference in reported falls by type of profile. The percentage of falls is calculated by dividing the number of falls reported by people in a profile by the total number of people in that profile. For example, 32 falls were reported by the 117 people in Profile 1 (27.4\%), thus accounting for the greatest percentage of falls. This percentage is followed by Profiles 2 , 4, and 3 (17.5, 14.7, and $13.0 \%$, respectively).

The location of the fall is strongly associated with characteristics of the profile. Taking into account the number of people in each profile, the percentage reporting an indoor fall ranged from $18.8 \%$ in Profile 1 to $6.0 \%$ in Profile 2 . In contrast, $11.4 \%$ of people in Profile 2 reported an outdoor fall, compared to approximately $6 \%$ in Profile 3. Among the 208 people who could not be classified 
TABLE 3 | Total number of falls past 6 months by profile.

\begin{tabular}{|c|c|c|c|c|c|c|c|}
\hline & Profile 1 & Profile 2 & Profile 3 & Profile 4 & Mixed & Total & $p$ Value \\
\hline & $\begin{array}{l}\text { Frail older adults/ } \\
\text { poor neighborhood } \\
\text { walkability }(n=117)\end{array}$ & $\begin{array}{l}\text { Healthy older adults/ } \\
\text { good neighborhood } \\
\text { walkability }(n=166)\end{array}$ & $\begin{array}{l}\text { Cognitively impaired } \\
\text { older adults/moderate } \\
\text { neighborhood walkability } \\
\text { ( } n=169)\end{array}$ & $\begin{array}{l}\text { Healthy older adults/ } \\
\text { poor neighborhood } \\
\text { walkability }(n=217)\end{array}$ & & & \\
\hline & $n(\%)$ & $n(\%)$ & $n(\%)$ & $n(\%)$ & $n(\%)$ & $n(\%)$ & \\
\hline All falls $(n=165)^{\mathrm{a}}$ & $32(27.4)$ & $29(17.5)$ & $22(13)$ & $32(14.7)$ & $50(23.9)$ & $165(18.8)$ & $p<0.01$ \\
\hline Indoor falls $(n=80)$ & $22(18.8)$ & $10(6)$ & $12(7.1)$ & $17(7.9)$ & $19(9.1)$ & $80(9.1)$ & $p<0.01$ \\
\hline $\begin{array}{l}\text { Outdoor falls } \\
(n=83)\end{array}$ & $10(8.5)$ & $19(11.4)$ & $10(5.9)$ & $14(6.5)$ & $30(14.4)$ & $83(9.5)$ & $p=0.02$ \\
\hline
\end{tabular}

a Locations of 2 falls were not identified.

in Profile 1, 2, 3, or 4, 9.1\% reported an indoor fall and 14.4\% reported an outdoor fall. These results indicate that over twice as many of the falls reported by people in Profile 1 occurred indoors than outdoors (18.8 vs. $8.5 \%)$. In contrast, more of the falls reported by people in Profile 2 happened outdoors than indoors (11.4 vs. 6.0\%). For those in Profile 3, the likelihood of an indoor fall is slightly more common than an outdoor fall (7.1 vs. 5.9\%). Finally, unlike the relatively healthy adults in Profile 2, the seemingly healthy people in Profile 4 report slightly more falls occurring indoors than outdoors (7.9 vs. $6.5 \%$ ).

\section{DISCUSSION}

Profiles 1 and 2 are very similar to the iconic types of fallers described in the current literature: frail older adults who are likely to fall indoors; healthy older adults who are likely to fall outdoors.

Profiles 1 and 2 also provide new information. The neighborhood environment in Profile 1, often ignored in studies of frail seniors at risk of falling, may discourage older adults from spending time outdoors. By spending more time at home, they are more likely to fall there. If Profile 1 respondents do leave their homes, they may be subject to hazards that may elevate the risk for a fall. Compared to the other profiles, Profile 2 is characterized by both the most walkable neighborhoods, based on both self-reported and objective measures; and, interestingly, the greatest proportion of outdoor falls. Walkable neighborhoods by definition encourage walking. If older adults feel at ease, they may be less likely to expect a hazard, such as a broken sidewalk, however rare that might be. Walkable neighborhoods also may encourage a larger number of walkers, thus elevating the risk of a fall from a collision or an attempt to avoid a collision with other pedestrians.

Although Profiles 1 and 2 most closely resemble the iconic indoor and outdoor fallers, these profiles account for less than half of the total number of falls in our sample (37.0\%). These results suggest that there may be other sets of risk factors (profiles) beyond the two most commonly reported in the literature. Profiles 3 and 4 suggest new combinations of risk factors not previously reported.

Profile 3 includes older people who are characterized by reasonably good physical health, but limited cognitive function. This may represent a curious combination of "positive" and "negative" factors that may elevate the risk of a fall (e.g., good lower body function and mild cognitive impairment, respectively), previously described by Bergland et al. (3). Future analytic studies should focus on the role of cognitive factors in different neighborhood settings. It is important to note that the respondents in this study were sufficiently cognitively and physically functional to attend a senior center, the site of study selection. Even though a respondent may fall in the lower study distribution of cognitive function, he or she was still quite functional to function independently and complete the interview and direct performance tests.

Profile 4 accounts for almost $25 \%$ of the respondents. Unlike respondents in Profile 2, whom they resemble in terms of good health and functioning, those in Profile 4 live in areas of low walkability. Problems with walkability do not seem to be associated with concerns about safety for people in Profile 4, as is the case with Profiles 1 and 3. In fact, respondents in Profile 4 are likely to report that their neighborhoods are safe and free from crime. These respondents are likely to live in suburban areas with low housing density, reduced access to services, and few walking destinations. However, given their relative affluence and reported ease in driving and parking, people in Profile 4 may not be troubled or inconvenienced by goods and services being beyond walking distance. Interestingly, overall falls, especially outdoor falls are more common in Profile 2 than Profile 4, even though the health and functional status of people in both profiles is relatively positive. It may be that walkable environments, as included in Profile 2, may encourage more everyday ("utilitarian") walking and ironically elevate the risk of an outdoor fall (32).

\section{Limitations}

This is a very promising avenue for research, but there are a number of limitations. First, this is a cross-sectional, descriptive analysis. Although we can identify higher order interactions, it is not possible to specify causal connections. Second, as noted previously, the measure of self-reported falls has been used in other projects there are still significant limitations. Our measure only records whether a respondent has fallen within a 6-month period. It is unclear how many times a respondent may have during that period. We also do not have information about the circumstances of the fall, critical for assessing the interaction with the neighborhood environment. 


\section{New Directions for Prevention}

The results support the call to better characterize the heterogeneity of falls $(4,6)$. A greater appreciation of the heterogeneity of falls should lead to a new set of more targeted and sophisticated prevention strategies. While strategies to improve balance and mobility are important, they are probably not sufficient for all older adults. Including information about the neighborhood context should provide valuable information to refine prevention strategies. GoM seems to represent a promising approach in this regard. New risk profiles may emerge and one or more of the current four profiles may recede or become more precise within the examination of larger and more diverse populations of older adults as well the examination of new risk information. The results of this study, although limited by the variable in the current data set, underscore the value of looking jointly at the intersection of the individual and the environment. For example, although neighborhood walkability has been shown to be associated with the risk of falls $(5,33,34)$, there is need for a more systematic and detailed examination of the interplay of neighborhood walkability, the functional capacity of older adults, and the location and circumstances of falls. There is a growing interest in the intersection with neighborhood characteristics (35). Research of this kind may suggest that older adults who live in "walkable environments," need special attention. With an anticipated increase in the volume and diversity of fellow pedestrians in walkable neighborhoods, older adults may need special instruction in the "rules of the sidewalk," not unlike ensuring that older drivers are conversant with the "rules of the road." Of course, this does not preclude direct environmental interventions to install walking and passing lanes to improve safe mobility.

More sophisticated prevention strategies, no doubt, will come from more sophisticated prevention-based research. This may be established in several ways:

1. It is necessary to obtain more detailed information on the timing, location, and circumstances associated with a fall. A life-space approach may be ideally suited for this task (36). This approach is designed to obtain information about a person's daily activities and movement from the bedroom, to other locations in the house, to the immediate yard and neighborhood, and beyond. Although originally designed to assess and compare the level of mobility of older adults, it is ideally suited to learn more about older adults' timing, location, and circumstances of regular activities. This information provides a very useful everyday context to then collect information about falls. In this case, we are not highlighting indoor and outdoor falls, but rather the number and location of falls than occur as part of everyday life.

\section{REFERENCES}

1. Rubenstein LZ, Josephson KR. Falls and their prevention in elderly people: what does the evidence show? Med Clin North Am (2006) 90(5):807-24. doi:10.1016/j.mcna.2006.05.013

2. Bergen C, Stevens MR, Burns ER. Falls and fall injuries among adults aged $\geq 65$ years - United States, 2014. MMWR Morb Mortal Wkly Rep (2016) 65(37):993-8. doi:10.15585/mmwr.mm6537a2

3. Bergland A, Jarnlo GB, Laake K. Predictors of falls in the elderly by location. Aging Clin Exp Res (2003) 15(1):43-50. doi:10.1007/BF03324479
2. While information on life space and falls can be obtained from self-report, it is also necessary to explore the utility of mobile, information technology to unobtrusively monitor the actions of the subjects (37). It is possible to use small wearable devices to monitor unobtrusively mobility and capture, record, and transmit abrupt movements associated with a fall.

In conclusion, research on risk profiles for falls underscores the utility of looking at the intersection of people and places. In addition to improving our understanding of the etiology of different types of falls, research in this area should lead to a new generation of prevention strategies that take into account both people and places.

\section{ETHICS STATEMENT}

Informed consent was obtained prior to the interview, as provided by the Institutional Review Board at each of the participating universities: University of California, Berkeley; University of Illinois, Chicago; University of Pittsburgh; and University of North Carolina, Chapel Hill.

\section{AUTHOR CONTRIBUTIONS}

All authors contributed equally.

\section{FUNDING}

This project was made possible through grants from the Robert Wood Johnson Foundation, Active Living Research Program (052515), and the CDC, Healthy Aging Research Network (CDC-U 48 DP00033-01). It also used data from the RAND Center for Population Health and Health Disparities (CPHHD), which is funded by Grant 1-P50-ES012383 from the National Institute of Environmental Health Sciences. For further information on CPHHD, see https://www.rand.org/health/centers/pophealth/ index.html. The content of this article is the responsibility of the authors and does not necessarily reflect the position of the Robert Wood Johnson Foundation, the CDC, or the RAND Center for Population Health and Health Disparities.

\section{SUPPLEMENTARY MATERIAL}

The Supplementary Material for this article can be found online at http://journal.frontiersin.org/article/10.3389/fpubh.2017.00142/ full\#supplementary-material.

4. Li W, Keegan THM, Sternfeld B, Sidney S, Quesenberry CP Jr, Kelsey JL. Outdoor falls among middle-aged and older adults: a neglected public health problem. Am J Public Health (2006) 96(7):1192. doi:10.2105/AJPH. 2005.083055

5. Chippendale T, Boltz M. The neighborhood environment: perceived fall risk, resources, and strategies for fall prevention. Gerontologist (2014) 55(4):575-83. doi:10.1093/geront/gnu019

6. Kelsey JL, Procter-Gray E, Hannan MT, Li W. Heterogeneity of falls among older adults: implications for public health prevention. Am J Public Health (2012) 102(11):2149-56. doi:10.2105/AJPH.2012.300677 
7. Speechley M, Tinetti M. Falls and injuries in frail and vigorous community elderly persons. J Am Geriatr Soc (1991) 39(1):46-52. doi:10.1111/j.15325415.1991.tb05905.x

8. Satariano WA, Ivey SL, Kurtovich E, Kealey M, Hubbard AE, Bayles CM, et al. Lower-body function, neighborhoods, and walking in an older population. Am J Prev Med (2010) 38(4):419-28. doi:10.1016/j.amepre.2009.12.031

9. Nagi SZ. An epidemiology of disability among adults in the United States. Milbank Mem Fund Q Health Soc (1976) 54(4):439-67. doi:10.2307/3349677

10. Rosow I, Breslau N. A Guttman health scale for the aged. J Gerontol (1966) 21:556-9. doi:10.1093/geronj/21.4.556

11. VanSwearingen JM, Brach JS. Making geriatric assessment work: selecting useful measures. Phys Ther (2001) 81(6):1233-52.

12. Barnes DE, Yaffe K, Satariano WA, Tager IB. A longitudinal study of cardiorespiratory fitness and cognitive function in healthy older adults. J Am Geriatr Soc (2003) 51(4):459-65. doi:10.1046/j.1532-5415.2003.51153.x

13. Billick SB, Siedenburg E, Burgert W, Bruni-Solhkhah SM. Validation of the Mental Alternation Test with the Mini-Mental State Examination in geriatric psychiatric inpatients and normal controls. Compr Psychiatry (2001) 42(3):202-5. doi:10.1053/comp.2001.23146

14. Folstein MF, Folstein SE, McHugh PR. "Mini-mental state": a practical method for grading the cognitive state of patients for the clinician. J Psychiatr Res (1975) 12(3):189-98. doi:10.1016/0022-3956(75)90026-6

15. Reitan RM. Validity of the trail making test as an indicator of organic brain damage. Percept Mot Skills (1958) 8(3):271-6. doi:10.2466/pms.1958.8.3.271

16. Andresen EM, Malmgren JA, Carter WB, Patrick DL. Screening for depression in well older adults: evaluation of a short form of the CES-D (Center for Epidemiologic Studies Depression Scale). Am J Prev Med (1994) 10(2):77-84.

17. Saelens BE, Sallis JF, Black JB, Chen D. Neighborhood-based differences in physical activity: an environment scale evaluation. Am J Public Health (2003) 93(9):1552-8. doi:10.2105/AJPH.93.9.1552

18. Guralnik JM, Ferrucci L, Simonsick EM, Salive ME, Wallace RB. Lowerextremity function in persons over the age of 70 years as a predictor of subsequent disability. N Engl J Med (1995) 332(9):556-62. doi:10.1056/ NEJM199503023320902

19. Guralnik JM, Simonsick EM. Physical disability in older Americans. J Gerontol (1993) 48 Spec No:3-10. doi:10.1093/geronj/48.Special_Issue.3

20. Guralnik JM, Simonsick EM, Ferrucci L, Glynn RJ, Berkman LF, Blazer DG, et al. A short physical performance battery assessing lower extremity function: association with self-reported disability and prediction of mortality and nursing home admission. J Gerontol (1994) 49(2):M85-94. doi:10.1093/ geronj/49.2.M85

21. Guralnik JM, Ferrucci L, Pieper CF, Leveille SG, Markides KS, Ostir GV, et al. Lower extremity function and subsequent disability: consistency across studies, predictive models, and value of gain speed alone compared with the short physical performance battery. J Gerontol A Biol Sci Med Sci (2000) 55(4):M221-31. doi:10.1093/gerona/55.4.M221

22. Cerin E, Saelens BE, Sallis JF, Frank LD. Neighborhood Environment Walkability Scale: validity and development of a short form. Med Sci Sports Exerc (2006) 38(9):1682-91. doi:10.1249/01.mss.0000227639.83607.4d

23. Nagel CL, Carlson NE, Bosworth M, Michael YL. The relation between neighborhood built environment and walking activity among older adults. Am J Epidemiol (2008) 168(4):461-8. doi:10.1093/aje/kwn158

24. Andreotti A, Minicuci N, Kowal P, Chatterji S. Multidimensional profiles of health status: an application of the grade of membership model to the
World Health Survey. PLoS One (2009) 4(2):e4426. doi:10.1371/journal. pone. 0004426

25. Gu D, Zeng Y. Healthiness of survival and quality of death among oldest old in China using fuzzy sets. JAging Health (2012) 24(7):1091-130. doi:10.1177/0898264312453069

26. Maetzel A, Johnson SH, Woodbury M, Bombardier C. Use of grade membership analysis to profile the practice styles of individual physicians in the management of acute low back pain. J Clin Epidemiol (2000) 53(2):195-205. doi:10.1016/S0895-4356(99)00120-1

27. Pomarol-Clotet E, Salvador R, Murray G, Tandon S, McKenna PJ. Are there valid subtypes of schizophrenia? A grade of membership analysis. Psychopathology (2010) 43(1):53-62. doi:10.1159/000260044

28. Erosheva EA. Comparing latent structures of the grade of membership, Rasch, and latent class models. Psychometrika (2005) 70(4):619-28. doi:10.1007/ s11336-001-0899-y

29. Erosheva EA. Latent Class Representation of the Grade of Membership Model. Seattle: University of Washington (2006).

30. Berkman L, Singer B, Manton K. Black/white differences in health status and mortality among the elderly. Demography (1989) 26(4):661-78. doi:10.2307/ 2061264

31. Bath PA, Morgan K. Differential risk factor profiles for indoor and outdoor falls in older people living at home in Nottingham, UK. Eur J Epidemiol (1999) 15(1):65-73. doi:10.1023/A:1007531101765

32. Li W, Procter-Gray E, Lipsitz LA, Leveille SG, Hackman H, Biondolillo M, et al. Utilitarian walking, neighborhood environment, and risk of outdoor falls among older adults. Am J Public Health (2014) 104(9):e30-7. doi:10.2105/ AJPH.2014.302104

33. Gallagher NA, Clarke PJ, Ronis DL, Cherry CL, Nyquist L, Gretebeck KA. Influences on neighborhood walking in older adults. Res Gerontol Nurs (2012) 5(4):238. doi:10.3928/19404921-20120906-05

34. Merom D, Gebel K, Fahey P, Astell-Burt T, Voukelatos A, Rissel C, et al. Neighborhood walkability, fear and risk of falling and response to walking promotion: the easy steps to health 12 -month randomized controlled trial. Prev Med Rep (2015) 2:704-10. doi:10.1016/j.pmedr.2015.08.011

35. Lo AX, Rundle AG, Buys D, Kennedy RE, Sawyer P, Allman RM, et al. Neighborhood disadvantage and life-space mobility are associated with incident falls in community-welling older adults. J Am Geriatr Soc (2016) 64(11):2218-25. doi:10.1111/jgs.14353

36. Stalvey BT, Owsley C, Sloane ME, Ball K. Life space questionnaire: a measure of the extent of mobility of older adults. J Appl Gerontol (1999) 18(4):460-78. doi:10.1177/073346489901800404

37. Satariano WA, Scharlach AE, Lindeman D. Aging, place, and technology: toward improving access and wellness in older populations. J Aging Health (2014) 26:1373-89. doi:10.1177/0898264314543470

Conflict of Interest Statement: The authors declare that the research was conducted in the absence of any commercial or financial relationships that could be construed as a potential conflict of interest.

Copyright (c) 2017 Satariano, Wang, Kealey, Kurtovich and Phelan. This is an open-access article distributed under the terms of the Creative Commons Attribution License (CC BY). The use, distribution or reproduction in other forums is permitted, provided the original author(s) or licensor are credited and that the original publication in this journal is cited, in accordance with accepted academic practice. No use, distribution or reproduction is permitted which does not comply with these terms. 